\title{
PLEXOS CORÓIDES: ESTUDO HISTOPATOLÓGICO EM DIFERENTES FAIXAS ETÃRIAS
}

\author{
DEISE REGINA MAFFAZZONI * \\ LIGIA MARIA BARBOSA-COUTINHO **
}

Os plexos coróides têm importante papel na formação do liquido céfalo-raquidiano. Seu aspecto histopatológico apresenta modificaçōes que variam desde a vida fetal até a vida adulta. Essas estruturas são formadas pela invaginação do epêndima para dentro das cavidades ventriculares, provocada pelos vasos da pia-máter. A origem do epitélio coroidal a partir do epêndima é evidenciada pelo aspecto das células que revestem o eixo conjuntivo-vascular que, na vida fetal, constituem um epitélio colunar pseudo-estratificado. A transformação dessas células colunares em cubóides, caracteristicas dos plexos coróides maduros, pode ser observada a partir do sétimo mês de vida intra-uterina.

O propósito deste trabalho é observar o aspecto histológico dos plexos coróides nas diferentes fases da vida, incluindo neste estudo desde fetos a pessoas adultas.

\section{MATERIAL E METODOS}

Foram estudados 146 plexos coróides provenientes de autópsias realizadas no Depar. tamento de Patologia da FFFCMPA no periodo compreendido de janeiro de 1983 a outubro de 1984.

Os encéfalos foram fixados em formalina a $10 \%$ e seccionados transversalmente. Os plexos coróides dos ventrículos laterais foram retirados com o auxílio de pinça, examinados macroscopicamente e, após, inclúdos em parafina para seçăo em micrótomo da American Optical Coorporation, na espessura de 5 micra. Foram corados pela Hematoxilina-Eosina. As alteraçoes histológicas foram observadas e analisadas segundo o parâmetro das idades dos pacientes.

\section{RESULTADOS}

As idades dos pacientes oscilaram de 26 semanas de vida intra-uterina a 87 anos A distribuiça dos pacientes conforme as idades é mostrada na tabela 1 (Fig. 1). A análise histológica seguirá a ordem cronológica dos casos estudados e está resumida na tabela 2.

Iniciaremos com a descrição dos plexos coróides de fetos. Estes se apresentaram com vasos dilatados, e, muitas vezes, congestos. A parede dos capilares era fina, com escassa quantidade de substância fundamental entre ela e o epitélio cuboidal que revestia os plexos. A congestão mostrou-se mais acentuada naqueles fetos que apresentaram hemorragia subependimária ou intraventricular. Em um caso, observou-se

Trabalho realizado no Departamento de Patologia da Fundação Faculdade Federal de Ciências Médicas de Porto Alegre (FFFCMPA): * Medica-Residente: ** ProfessoraAdjunta, Pesquisadora do CNPq. 


\begin{tabular}{lc}
\hline \multicolumn{1}{c}{ Idade } & Número de casos \\
Fetos & 26 \\
Recém-nascidos & 33 \\
até 1 ano & 4 \\
de 1 a 2 anos & 14 \\
de 2 a 10 anos & 3 \\
de 11 a 20 anos & 7 \\
de 21 a 30 anos & 14 \\
de 31 a 40 anos & 23 \\
de 41 a 60 anos & 12 \\
de 61 a 80 anos & 3 \\
mais de 80 anos & 146 \\
Total & \\
\hline
\end{tabular}

Tabela 1 - Distribuica dos casos conforme a idade.

\section{DISTRIBUIÇÃO DOS CASOS CONFORME A IDADE}

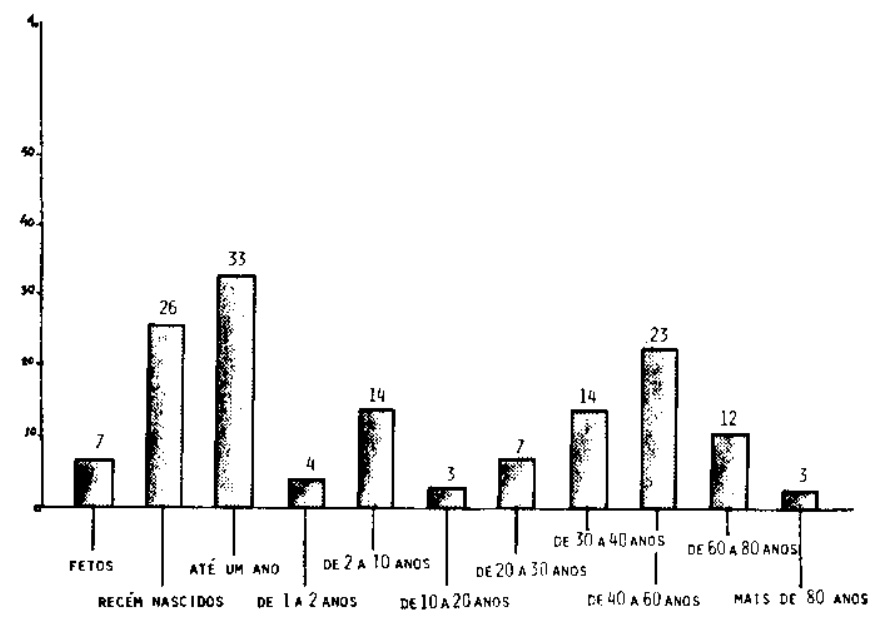

Fig̣, 1 - Distribuição dos casos conforme a idade (v. tabela 1 ).

vacuolização das células cúbicas epitellais, acompanhada de aumento de volume do corpo celular, com deslocamento do núcleo da célula para a periferia (Fig. 2 A).

Os plexos coróides de recém-nascidos năo diferiram fundamentalmente dos plexos coróides fetals. Apresentaram as vilosidades coroidals atapetadas por células cúbicas, contendo vasos com paredes delicadas e finas, com luz dilatada (Fig. 2 B). Observou-se, na regiāo próxima ao glomus, a presença de material de aspecto eosinofílico e homogêneo, no espaço extra-celular, em três $(11,5 \%)$ dos 26 casos estudados. Em um recém-nascido prematuro, as celulas epiteliais se encontravam aumentadas de volume, 


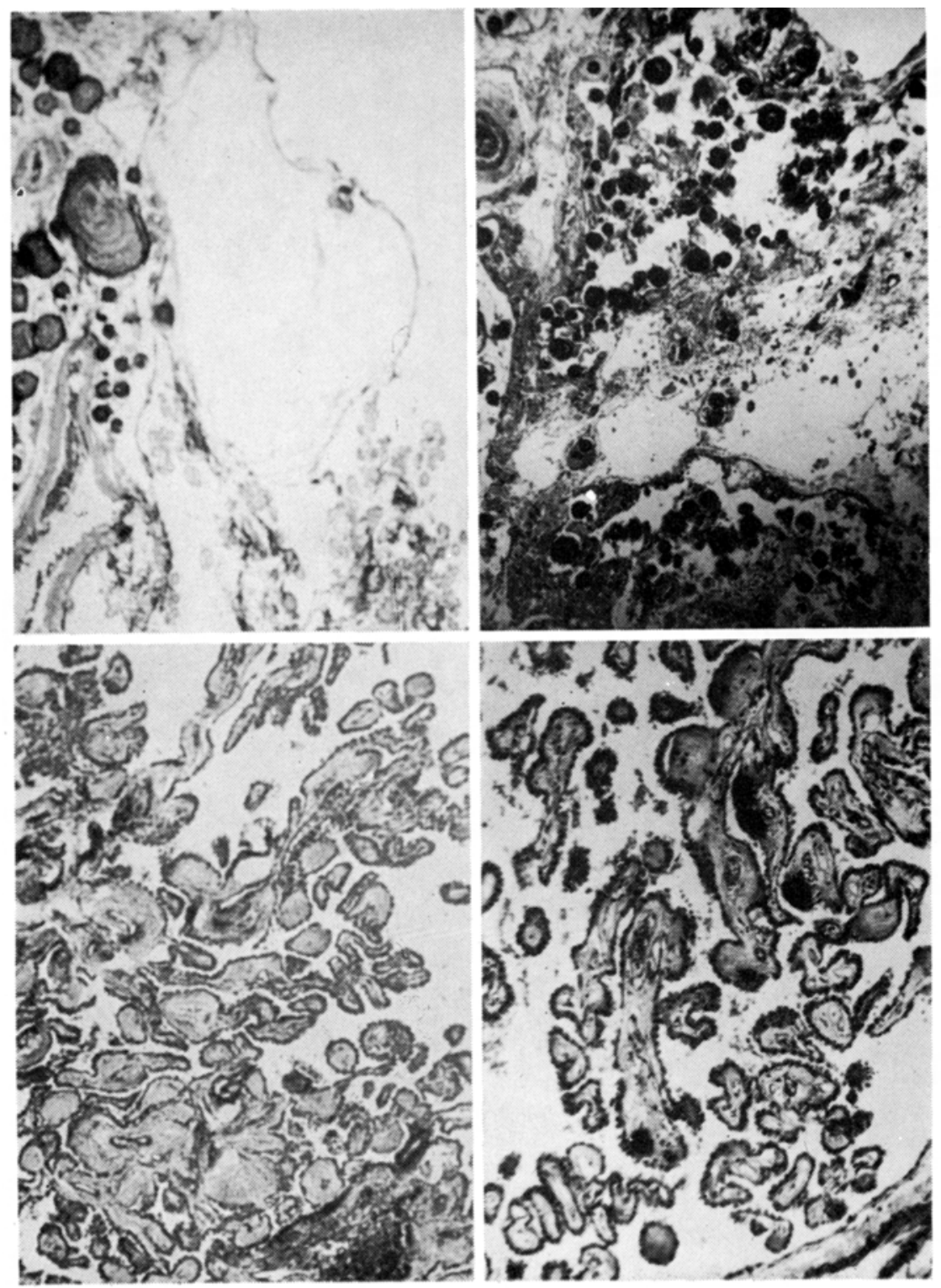

Fig. 2-Em A (no alto, à esquerda), vê-se a vacuoliząão do epitélio cúbico dos plexos corbides de um feto recém-nascido prematuro. Em $B$ (no alto, d̀ direita), observa-se o epitélio cúbico e os vasos dilatados e congestos, com paredes finas e delicadas, em um recém-nascido. Em C (em baixo, à esquerda), o glomus do plexo corbide esta demonstrado, com vasos de paredes delicadas, em uma criança de 9 meses. Em $D$ (em baixo, à direita), pode-se ver duas pequenas calcificacóes à direita da foto, no plexo corbide de uma criança de 4 meses de idade. 


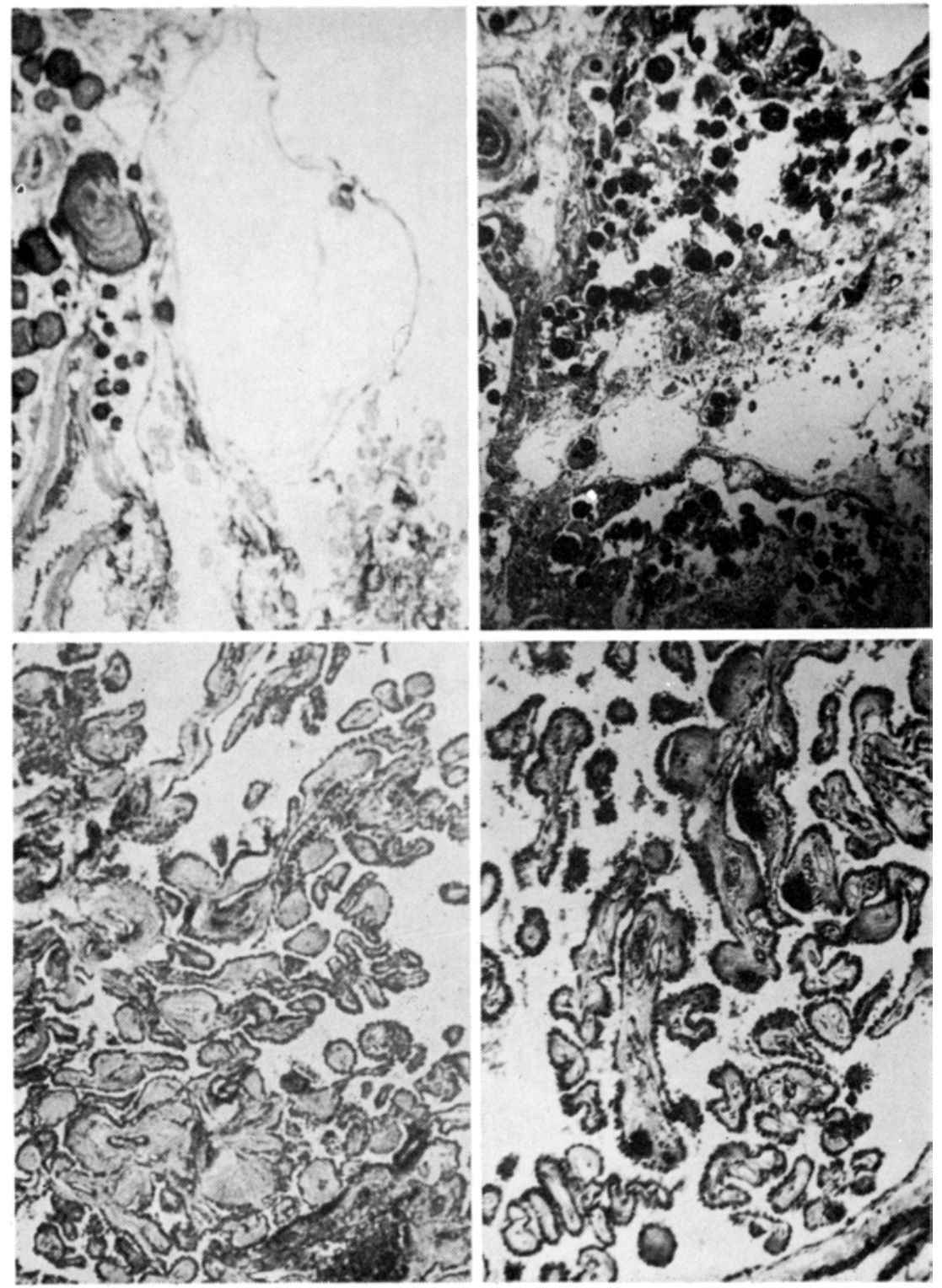

Fig. $s$ - Em A (no alto, à esquerda), veem-se calcificacões concêntricas localizadas no glomus $e$ area de degenerąão cistica, em um paciente de 20 anos de idade. $E m B$ (no alto, à direita), as oalcificaç̃es são mais numerosas a partir dos 30 anos de idade e localizam-se no glomus. Em $C$ (em baixo, à esquerda), observa-se degeneração hialina dos vilos corbideos, que são mais constantes a partir da quarta década da vida. Em $D$ (em baixo, a direita), pode-se verificar a presença de areas de calcificaçô nos vilos previamente hialinizados, também a partir dos 30 anos de idade. 


\begin{tabular}{|c|c|c|c|c|c|c|c|c|c|}
\hline & Feto & $\begin{array}{l}\text { Recém- } \\
\text { nascido }\end{array}$ & $1 \mathrm{~m}-1 \mathrm{a}$ & $1-10 a$ & $10-30 a$ & $30-40 a$ & $40-60 a$ & $60-80 a$ & $\begin{array}{l}\text { mais } \\
\text { de } 80 a\end{array}$ \\
\hline $\begin{array}{l}\text { Material } \\
\text { eosinofilico } \\
\text { intersticial }\end{array}$ & - & $\begin{array}{r}11,5 \\
(3)\end{array}$ & $\begin{array}{r}11,7 \\
(4)\end{array}$ & $\begin{array}{l}5,5 \\
(1)\end{array}$ & - & - & - & - & - \\
\hline $\begin{array}{l}\text { Calcificação } \\
\text { do glomus }\end{array}$ & - & $\begin{array}{l}3,8 \\
(1)\end{array}$ & $\begin{array}{c}26,4 \\
(9)\end{array}$ & $\begin{array}{l}55,5 \\
(10)\end{array}$ & $\begin{array}{c}90,0 \\
(9)\end{array}$ & $\begin{array}{r}100,0 \\
(15)\end{array}$ & $\begin{array}{r}100,0 \\
(23)\end{array}$ & $\begin{array}{r}100,0 \\
(12)\end{array}$ & $\begin{array}{r}100,0 \\
(3)\end{array}$ \\
\hline $\begin{array}{l}\text { Hiailnização } \\
\text { de vilos }\end{array}$ & - & - & - & - & $\begin{array}{c}30,0 \\
(3)\end{array}$ & $\begin{array}{c}100,0 \\
(15)\end{array}$ & $\begin{array}{c}100,0 \\
(23)\end{array}$ & $\begin{array}{c}100,0 \\
(12)\end{array}$ & $\begin{array}{r}100,0 \\
(3)\end{array}$ \\
\hline $\begin{array}{l}\text { Calcificação } \\
\text { de vilos }\end{array}$ & - & - & - & - & 一 & $\begin{array}{l}86,6 \\
(13)\end{array}$ & $\begin{array}{c}100,0 \\
(23)\end{array}$ & $\begin{array}{c}100,0 \\
(12)\end{array}$ & $\begin{array}{c}100,0 \\
(3)\end{array}$ \\
\hline $\begin{array}{c}\text { Calcificaçöes } \\
\text { grosseiras }\end{array}$ & - & - & - & - & $\begin{array}{r}10,0 \\
(1)\end{array}$ & $\begin{array}{l}6,6 \\
(1)\end{array}$ & - & 一 & - \\
\hline $\begin{array}{l}\text { Degeneração } \\
\text { cística }\end{array}$ & 一 & - & $一$ & $\begin{array}{r}16,6 \\
(3)\end{array}$ & $\begin{array}{r}30,0 \\
(3)\end{array}$ & $\begin{array}{r}60,0 \\
(9)\end{array}$ & $\begin{array}{l}43,4 \\
(10)\end{array}$ & $\begin{array}{r}100,0 \\
(12)\end{array}$ & $\begin{array}{r}100,0 \\
(3)\end{array}$ \\
\hline $\begin{array}{l}\text { Calcificação de } \\
\text { paredes vasculares }\end{array}$ & - & - & - & - & - & 一 & 一 & - & $\begin{array}{c}33,3 \\
(1)\end{array}$ \\
\hline $\begin{array}{l}\text { Aglomerado de cé- } \\
\text { lulas histiocíticas }\end{array}$ & - & - & $\begin{array}{l}2,9 \\
(1)\end{array}$ & - & $\begin{array}{r}10,0 \\
(1)\end{array}$ & $\begin{array}{l}6,6 \\
(1)\end{array}$ & - & - & - \\
\hline $\begin{array}{l}\text { Infiltrado } \\
\text { inflamatorio }\end{array}$ & - & - & $\begin{array}{l}5,8 \\
(2)\end{array}$ & - & - & $\begin{array}{r}13,3 \\
(2)\end{array}$ & $\begin{array}{l}8,6 \\
(2)\end{array}$ & $\begin{array}{l}8,3 \\
(1)\end{array}$ & - \\
\hline Hemorragia & - & - & - & - & - & $\begin{array}{l}6,6 \\
(1)\end{array}$ & - & - & - \\
\hline Pigmento malárico & - & - & - & 一 & - & $\begin{array}{l}6.6 \\
(1)\end{array}$ & - & - & - \\
\hline
\end{tabular}

Tabela 2 - Aspectos histologicos encontrados nos plexos corbides, de acordo com a idade ( $m$, mes; a, anos).

com citoplasma opticamente vazio e núcleo rechaçado para a periferia. Surpreendentemente visualizou-se a presença de raros pequenos psamomas, locallzados na regiấ do glomus, em uma criança recém-nascida $(3,8 \%)$.

As crianças até um ano de vida ( 34 casos) apresentaram plexos coróides bem constituídos, com epitélio cúbico, vasos congestos de paredes delicadas (Fig. 2 C). Em 4 casos $(11,7 \%$ ) havia material eosinofílico e homogêneo no espaço extracelular, especialmente na região do glomus. Em 9 casos $(26,4 \%)$ pode-se evidenciar a presença de calcíftcaçoses concêntricas na zona próxima ao glomus (Fig. 2 D). O paciente mais jovem que apresentava psamomas tinha 4 meses. Em um caso $(2,9 \%)$ células histiocíticas foram visualizadas na regiāo do glomus. Em dois casos $(5,8 \%)$ havia infiltração inflamatória por neutrófilos nos plexos coróides, em pacientes com meningite purulenta.

No grupo de pacientes com idades de um a 10 anos (18 casos), $10(55,55 \%)$ apresentaram raras e pequenas calcificaçōes sob a forma de psamomas e três $(16,6 \%)$ tinham focos de degeneração microscítica, ambas localizadas na região do glomus. Em um caso $(5,5 \%)$ evidenciou-se presença de material easinofílico e homogêneo na região próxima ao glomus. 
Nas idades de 10 a 20 anos foram estudados apenas três casos e 7 pacientes apresentaram de 20 a 30 anos. Como as alterações encontradas nesses grupos de pacientes foram praticamente superponiveis, elas serăo descritas em conjunto. Desses 10 casos, em $9(\mathbf{9 0 \%})$ havia calcificaçóes concêntricas (Fig. 3 A), em um dos quais se associou calcificaçăo grosseira. A degeneraçăo cística foi encontrada em três casos (30\%), em um dos quais havia associação com conglomerado de células histiociticas no glomus. Neste grupo de pacientes, pode-se observar um aumento da substância fundamental situada entre as paredes dos vasos capilares dos vilos e o epitélio cúbico, representado pelo aspecto de hialinização das vilosidades (três casos, $30 \%$ ).

Na faixa etária dos 30 a 40 anos (15 casos), os plexos coróides apresentam-se sistematicamente $(\mathbf{1 0 0 \%})$ com calcificaçōes, sob a forma de psamomas, geralmente presentes em grande número, especialmente na regiāo do glomus coróideo (Fig. 3 B). Em um caso $(6,6 \%)$ a calcificação apresentou-se de forma grosseira nessa localização. A hialinização dos vilos, vista esporadicamente no grupo anterior, tornou-se mais intensa e constante neste grupo (Fig. $3 \mathrm{C}$ ). O mesmo aconteceu com a presenca de degeneração cistica, que estava presente em 9 casos $(60 \%)$. Associada à presença de áreas maís extensas de hialinização dos vilos, observou-se, em 13 casos $(86,6 \%)$, a deposição de sals de cálcio nos vilos previamente hialinizados (Fig. $3 \mathrm{D}$ ). Infiltração inflamatória neutrofilica estava presente em dois casos $(13,3 \%)$, ambos com meningite purulenta. $\mathrm{Em}$ um caso $(6,6 \%)$, aglomerado de histiócitos na região do glomus foi visualizado. Em outro $(6,6 \%)$ havia hemorragia em plexos coróides e, em um terceiro $(6,6 \%)$, pode-se visualizar o pigmento malárico nas células endoteliais dos capilares e dentro das hemácias, em paciente com malária.

Nas idades de 40 a 60 anos (23 casos) os plexos coróides encontravam-se calcificados em $100 \%$ dos casos examinados, o mesmo acontecendo com a hialinização de vilos e presença de calcificaçāo deles. A degeneraçăo cística ocorreu em 10 casos $(43,4 \%)$ e a infiltração inflamatória foi observada em dois pacientes $(8,6 \%)$ com meningite purulenta.

Nas idades de 60 a 80 anos também evidenciou-se $100 \%$ de calcificaçăo, sob a forma de psamomas, que predominaram na região do glomus (Fig. 4 A). A calcificação, também sob a forma de psamomas, fez-se presente nos vilos, de forma mais constante e acentuada $(100 \%)$. A degeneração cística foi comparável às duas faixas anteriores (Fig. 4 B). Havia infiltração lcucocitária $€ \mathrm{~m}$ um caso $(8,3 \%)$ de meningite.
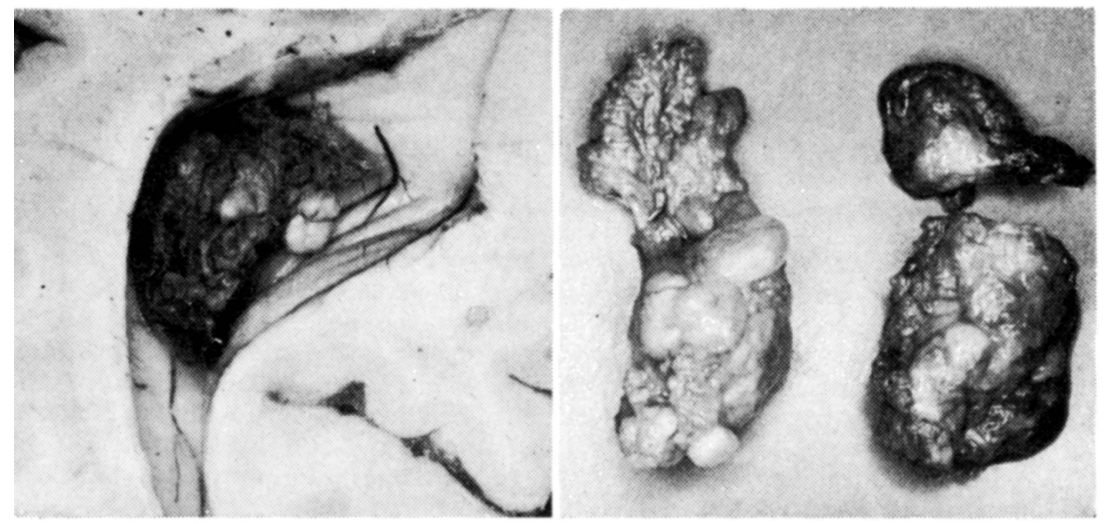

Fig. 4 - Em A (esquerdia), aspecto macroscópico do plaxo coróide do ventriculo lateral direito, com áreas amarelo-esbranquiçadas, que correspondem às areas de calcificaç̃o. $E m$ B (direita), aspecto macroscópico das plexos corbides, em que se vêem áreas císticas e áreas de calcificação. 
Nos pacientes de mais de 80 anos a presença de psamomas na regiảo do glomus, a hialinização com calcificação dos vilos coróideos e a degeneração cística ocorreram na mesma frequêencia que a encontrada nas faixas etárias anteriormente descritas. Em um caso $(8,3 \%)$ havia calcificação das paredes vasculares. A incidência de calcificaçōes e degeneração cistica dos plexos coróides de acordo com as idades pode ser vista na figura 5 .

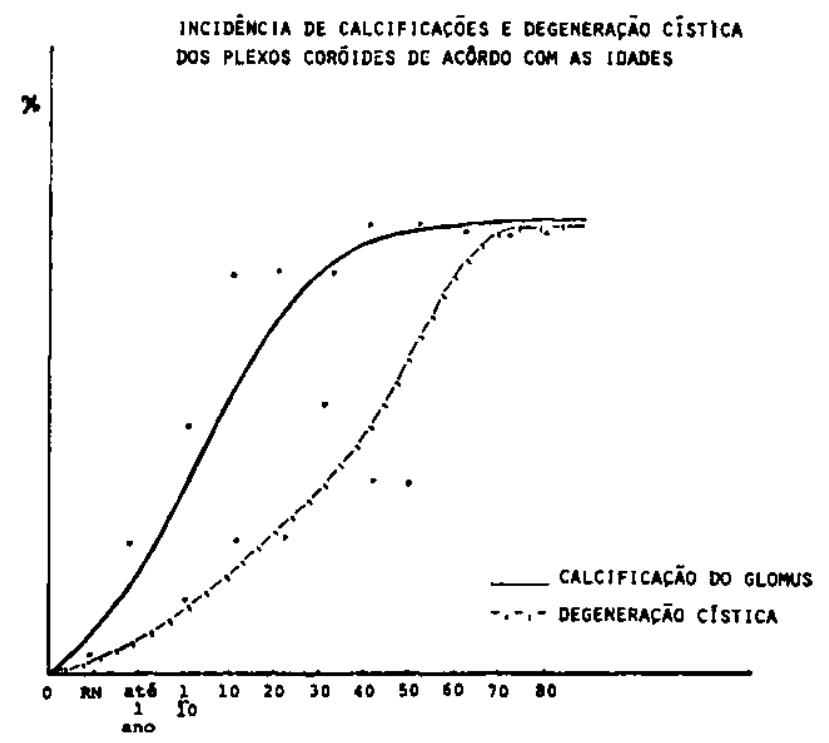

Fig. 5 - Incidencirs, de calcificaç⿰丿s e degeneraşäo cistioa dos plexos corbides de acordo com as idades.

\section{COMENTARIOS}

Apesar de alguns trabalhos existentes na literatura5 demonstrarem calcificações de plexos coróides em crianças de três anos de idade, este achado não é tão frequentemente encontrado na primeira década da vida, mesmo quando se utilizam meios diagnósticos tão sensiveis como a tomografia computadorizada3.5. Entretanto, quando se examinam microscopicamente os plexos coróides, podemos observar concreções calcárias em pessoas mais jovens, como ocorreu no presente trabalho, visualizando-se psamomas na região do glomus em crianças de 4 meses de idade e inclusive em um recém-nascido. No grupo de crianças até um ano de vida, em 9 dos 34 casos estudados pode-se observar calcificaçōes. Em dois desses pacientes havia concomitância de meningite purulenta. Becker 1 assinala o fato de doenças inflamatórias crônicas, como a tuberculose, determinarem atmento no número de psamomas nos plexos coróides, mas não comenta a associação com processos agudos.

O aparecimento de calcificaçōes aumentou na primeira década da vida, ocorrendo em $55,55 \%$ dos casos, todas elas localizadas na região do glomus. Enquanto que a tomografia computadorizada mostra calcificações dos plexos 
coróides em apenas $0,5 \%$ dos casos de crianças de um a 10 anos de idade o exame histológico revela indice de presença dessas estruturas de $55,55 \%$ dos casos examinados. Essa diferença demonstra que as calcificações dos plexos coróides quando esparsas e pouco numerosas aramente são evidenciadas por exames paraclínicos mesmo dos mais sensiveis, como a tomografia computadorizada.

$\mathrm{Na}$ segunda e terceira década, a frequência de calcificaçōes alcançou $90 \%$ todas com aspecto de psamomas, e, em um caso, havia associação com calcj. ficaçăo grosseira na regiāo do glomus. A partir da quarta década, as calcificações, sob a forma de psamomas, estão presentes em todos casos $(100 \%)$ em geral em grande número e localizadas na regiāo do glomus. Em dois casos ela foi grosseira. Associada à hialinização, que se torna constante $(100 \%)$ há calcificação dos vilos em $86,6 \%$ dos casos da quarta década, que passa a ser de $100 \%$ após a quinta década. A hialinizaçăo é, pois, condição que ante. cede à calcificaçăo, fato bem evidenciado no estudo desses pacientes. Já Virchou considerava os corpos psamomatosos como originados partir de restos de células que sofreram degeneração hialina e posterior depósito de cálcio. A loca. lização dos psamomas é classicamente descrita como na região do glomus ${ }^{4}$ entretanto, como foi demonstrado no presente trabalho, eles podem ser visua. lizados nos vilos, especialmente em pacientes acima de 30 anos d idade, que tenham apresentado degeneraçăo hialina dessas estruturas. Modic e col.5 referem que na oitava década da vida se evidencia uma frequência de calcificações de plexos coróides que alcança $86 \%$ dos casos examinados pela tomografia computadorizada, enquanto que no material estudado histologicamente a inci. dência alcança $100 \%$ dos casos na quarta década de vida. Já nessa fase da vida o número de psamomas é grande, superponivel, em média, ao encontrado nas outras faixas etárias. Desta forma já poderiam ser detectadas pela tomo. grafia computadorizada, pois esta possui maior sensibilidade que a radiografia do crànio na detenção dessé tipo de alteração $0^{3,5}$.

A presença de degeneração cística é frequentemente encontrada em indi. viduos velhos 4 , possivelmente decorrente de alterações que ocorrem pelo envelhecimento. Realmente o aspecto cistico dos plexos coróides é visto com maior frequência em individuos com mais de 30 anos, sendo rara sua presença antes dessa fase da vida. Em nossos casos, foi observada degeneração cística em um caso de criança com dois meses de idade e em três crianças com mais de 5 anos. Esses cistos localizam-se preferentemente na região do glomus ${ }^{4}$. O número e tamanho dos cistos são varáveis, podendo ocupar toda extensão dos plexos coróides. $O$ conteúdo geralmente é um liquido fluído e limpido. $O$ cisto não apresenta revestimento epitelial. Em grande número de casos, pode-se observar a presença de psamomás no interior das áreas císticas.

Em um feto e em um recém-nascido observou-se vacuolização das células epiteliais de revestimento dos plexos coróides, com aumento de volume do corpo celular e deslocamento do núcleo para a periferia da célula. Esse aspecto da célula pode ser devido à presença de glicogênio no interior do citoplasma celular A presença dessa substância tem sido relatada em epitélio coroidal imaturo de 
homens 2,6 , estando ausente nos plexos coróides totalmente desenvolvidos. Sugere-se que o glicogênio seria a fonte de energia, sob condiçōes anaeróbias². Realmente as células epiteliais coroidais podem ser um depósito lábil de glicogênio que serve para nutrir o encéfalo durante certos periodos de carência nutritiva 7 .

A presença de material eosinofílico intersticial no glomus dos plexos coróides pode significar a precipitação de substância fundamental que pode ocorrer em alguns casos?.

\section{RESUMO}

Os autores estudaram 146 casos de plexos coróides provenientes de autópsias realizadas no Departamento de Patologia da FFFCMPA, no período de janeiro de 1983 a outubro de 1984, com a finalidade de analisar as alteraçōes histopátológicas nas diferentes fases da vida. As idades dos pacientes estudados oscilaram de 26 semanas de vida intra-uterina a 87 anos. O estudo abrange 6 fetos, 26 recém-nascidos, 34 casos até um ano de idade, 4 de um a dois anos, 14 de 2 a 10 anos, 3 de 10 a 20 anos, 7 entre 20 a 30 anos, 14 de 30 a 40 anos, 23 de 40 a 60 anos, 12 de 60 a 80 anos e, três acima de 80 anos. A análise dos casos demonstrou diferenças quanto ao aspecto histopatológico dos plexos coróides, que variaram de células epiteliais vacuolizadas, presença de material eosinofílico no interstício - nos primeiros anos de vida - a calcificações restritas ao glomus e psamomas ou calcificaçōes grosseiras, cuja intensidade acentuou-se com o aumento da faixa etária.

\section{SUMMARY}

\section{Choroid plexus: an histopathological study at different ages.}

The authors studied 146 choroid plexus of patients that were autopsied at the Department of Pathology of FFFCMPA in the period of January 1983 to October 1984. They analysed the histopathological details at different ages and disclosed vacuolisation and presence of eosinophilic material in the interstitium of choroid plexus in the first years of life and calcification and cystic formation at the glomus of choroid plexus that were more accentuated in the older patients.

\section{REFERENCIAS}

1. BECKER, G. - Beiträge zur Orthologie und Pathologie der Plexus chorioidei und des Ependyms. Beitr. path. Anat. 103:457, 1939.

2. KAPPERS, J.A. - Structural and functional changes in the telencephalic choroid plexus during human ontogenesis. In G.E.W. Wolstenholme \& C.M. O'Connor (eds.): Ciba Foundation Symposium on Cerebrospinal Fluid. Boston, Little Brown \& Co., 1958, pg. 3 .

3. MACPHERSON, P. \& MATHESON, M.S. - Comparison of calcification of pineal, habenular comissure and choroid plexus on plain films and computed tomography. Neuroradiology $18: 67,1979$. 
4. MILLeN, J.W. \& WOOLLAM, D.H. - The Anatomy of the Cerebrospinal Fluid. Oxford Univ. Press, London, 1962, pg. 60.

5. MODIC, M.'.; WEINSTEIN, M.A.; ROTHNER, A.D.; ERENBERG, G.; DUCHESNEAU, P.M, \& KAUFMAN, B. - Calcification of the choroid plexus visualized by computed tomography, Radiology 135:369, 1980.

6. SHUANGSHOTY, S. \& NETSKY, M.G. - Histogenesis of choroid plexus in man. Amer. J, Anat. 118:283, 1966.

7. TENNYSON, V.M. - The diferences in fine structure of the myelencephalic and telencephalic choroid plexus in the fetuses of man and rabbit, and a comparison with the mature stages. In A.E. Walker \& R. Arana-Iñiguez: Cerebrospinal Fluid in the Health and Disease. Acta neurol. latinoamer. 17, suppl. 1:11, 1971.

Rua Carvalho Monteiro 414 - 90000 - Porto Alegre, RS - Brasil. 